\title{
Comparative analysis of sorption of small molecule hydrocarbons and polar substances in polish hard coals
}

\author{
Grzegorz Jodłowski • Marta Wójcik
}

Received: 15 November 2012/Accepted: 16 February 2013/Published online: 16 March 2013

(C) The Author(s) 2013. This article is published with open access at Springerlink.com

\begin{abstract}
The subject of the article is the thermodynamic analysis of the sorption of aliphatic hydrocarbons in hard coals from polish mines. The analysis is based on a Multisorption model designed for describing small molecule sorption in different types of carbonaceous materials (e.g. hard coals, lignites or active carbons). Experimental isotherms of hydrocarbons: hexane, heptane, octane and benzene, in hard coals of different rank, together with water and methanol vapor isotherms measured at room temperature $\left(25^{\circ} \mathrm{C}\right)$, are taken as comparative data for simulations. Results of the analyses reveal the complicated behavior of linear molecules in the sorption system. The location of molecules on the sorbent surface brings a spectrum of problems associated with the incomplete filling of pores, the coiling up of chains, the formulation of plates or globules, and the blocking of micropores. All these effects have an influence on the level and character of sorption, often in opposing ways. The sorption of small inorganic molecules is taken into account in the objective of achieving a more precise identification of the structure of coal. Semi-simultaneous computations for all types of sorbates have already been carried out.
\end{abstract}

Keywords Sorption - Adsorption - Absorption · Modeling · Hard coal · Organic solvent

G. Jodłowski $(\bowtie) \cdot$ M. Wójcik

AGH-University of Science and Technology, Faculty of Energy and Fuels, Al.A.Mickiewicza 30, 30-059 Kraków, Poland

e-mail: jodlowsk@agh.edu.pl

M. Wójcik

e-mail: mwojcik@agh.edu.pl

\section{Introduction}

Investigations of vapor recovery from hydrocarbon solvents or air purification from hydrocarbons have been carried out for many years (Fugassi et al. 1958; Shimizu et al. 1998; Breus et al. 2006; Belov et al. 2009; Shi et al. 2011). However there are not many publications explaining the principles behind the phenomenon of aliphatic molecules locating themselves on the surface of porous materials, especially geosorbents like hard coals. The aim of the investigations was to obtain knowledge about the character of the phenomenon of sorption of chain hydrocarbons in carbonaceous sorbents as "chip sorbents" in comparison to the sorption of cyclic ones. A secondary objective of the work is to check the applicability of the multiple sorption model (MSM) and its adequacy when applied to such complicated systems, in particular because it uses a model based on the spherical representation of sorption space at atomic scale (Duda and Milewska-Duda 1995).

It is a known fact that a partial elastic material (like hard coal) shows both adsorption and absorption in contact with small molecules. It is obvious that some intermediate phenomena occur in such a material. All the spectrum of sub-processes is taken into account in the MSM. Thorough thermodynamic analysis of the energy and entropy of the process lets our team determine a complicated model based on Flory's model of polymer solutions (Flory 1953).

\section{Experimental data}

The sorption isotherms of water, methanol, hexane, heptane, octane and benzene on different rank hard coals were measured using the following procedure. Coal probes with a grain size of $0.2 \mathrm{~mm}$ were inserted into liquid 
microburette equipment (Lason and Zyla 1963). Samples were degassed at a pressure of $10^{-3} \mathrm{~Pa}$, and following this the sorption isotherm measurement procedure was carried out at room temperature. Consecutive points of the isotherms were measured by dosing the sorbate vapor portion by opening the mercury valve, so producing a simultaneous increase in the pressure in the sorption space. Estimation of the amount of sorbed hydrocarbon (water or methanol) were determined on the basis of the vapor pressure measured before dosing, after dosing and after reaching the sorption equilibrium. Aliphatic hydrocarbons: hexane, heptane and octane, and aromatic hydrocarbons: benzene (Jodlowski and Wójcik 2003) as well as water and methanol were chosen for the measurements.

Accordingly to Flory's theory of polymer solutions (Flory 1953) and the copolymer model of the structure of hard coal, this substance is semi-rigid and partially elastic. So one would expect absorption or swelling phenomena to take place at a slow rate. Thus the equilibrium of each isotherm point is reached after about 2 days.

The characteristics of hard coals used for the experiment are presented in Tables 1 and 2. In Table 3 the characteristics of the sorbates are presented.

\section{Simulations}

Simulations are made using the MSM - a complicated numerical tool containing equations describing in a continuous manner all of the subprocesses, from absorption through the expansion phenomena in different sizes of

Table 1 Proximate and ultimate analysis of hard coal samples

\begin{tabular}{|c|c|c|c|c|c|c|c|}
\hline \multirow[t]{2}{*}{ Sample* } & \multicolumn{3}{|c|}{ Proximate analysis $(\%)$} & \multicolumn{4}{|c|}{ Ultimate analysis $(\%)$} \\
\hline & $\mathrm{A}^{\mathrm{a}}$ & $\mathrm{W}^{\mathrm{a}}$ & $\mathrm{V}^{\mathrm{daf}}$ & $\mathrm{C}^{\mathrm{daf}}$ & $\mathrm{H}^{\mathrm{daf}}$ & $(\mathrm{O}+\mathrm{N})^{\mathrm{daf}}$ & $\mathrm{S}_{\mathrm{t}}^{\mathrm{a}}$ \\
\hline W-31 & 2.60 & 8.75 & 39.20 & 75.16 & 5.56 & 19.28 & 0.62 \\
\hline W-33 & 2.00 & 2.03 & 30.30 & 83.31 & 5.10 & 8.60 & 0.30 \\
\hline W-35 & 4.80 & 0.72 & 24.40 & 86.85 & 4.65 & 6.51 & 1.53 \\
\hline
\end{tabular}

$A^{a}$ ash content in analytic state, $W^{a}$ water content in analytic state, $V^{\text {daf }}$ volatile matter in dry and ash free state

* names of the samples (numbers) correspond to the polish hard coal classification submicropores to adsorption on the surface of the porous material. The first subprocess is described by an equation that has been developed, Flory's equation of polymer solution. It has been expanded to include the case of a copolymer type of material taking into consideration the presence of a limited-rigid macromolecular network and quasi-crystalline objects called arene domains. These last have an effect on the configuration entropy of mixing by excluding the volume of arene domains from the sorption space. For technical reasons, the expansion area of the process is a priori divided into nine ranges. The last subprocess is adsorption, which is described by the multilayer adsorption equation with a limited quantity of molecules in several layers, similar to BET theory but derived from thermodynamic assumptions different from BET. The adsorption phenomenon is particularly interesting because of the different possible molecule locations on the surface (Milewska-Duda and Duda 1993, 2002a, b; Duda and Milewska-Duda 1995; Milewska-Duda et al. 2000a, b).

The experimental isotherms were used for a comparative simulation experiment: known trends in hard coal structure versus coal rank and properties of the sorbate were used as the basis for the simulation of the isotherm using MSM. The computation procedure is carried out until agreement is reached between the experimental and simulated isotherms.

At the molecular level, the reason that molecules are assigned to the subsystem is based on the quality (energy i.e. adhesive or cohesive character) and quantity of molecule (segment) contacts with other segments of the sorption system (e.g. macromolecular network, arene domains, molecular phase). It corresponds to the sorption system distribution on the spherical cells contacting each other with a network constant $\mathrm{z}$ varying from 6 to 12 (6 and less is adsorption, 12 is absorption, with reference to sorbate molecules). Therefore it is possible to account some segments of aliphatic chains to the expansion subsystem and the remainder to the adsorption one. The situation is further complicated by the fact, that some segments could be located in the submicropores (adsorption) and the remaining segments could occupy the surface blocking other pores or could stay free producing some kind of condensation centre for the next molecules. Another hypothesis is that there is conformation of the hydrocarbon chain in the neighborhood of the surface segments producing a plate-

Table 2 Microstructure analysis of hard coal samples

\begin{tabular}{|c|c|c|c|c|c|c|c|}
\hline \multirow[t]{2}{*}{ Sample } & \multicolumn{3}{|c|}{ Maceral group (\%) } & \multirow[t]{2}{*}{ Minerals (\%) } & \multicolumn{2}{|c|}{ Density $\left(\mathrm{g} / \mathrm{cm}^{3}\right)$} & \multirow[t]{2}{*}{ Porosity (\%) } \\
\hline & Vitrinite & Liptinite & Inertinite & & $\mathrm{Hg}$ & $\mathrm{He}$ & \\
\hline $\mathrm{W}-31$ & 69.40 & 8.90 & 20.60 & 1.10 & 1.343 & 1.617 & 7.40 \\
\hline W-33 & 57.00 & 7.50 & 26.00 & 10.50 & 1.336 & 1.403 & 4.78 \\
\hline W-35 & 78.00 & 0.30 & 19.00 & 2.70 & 1.305 & 1.399 & 6.67 \\
\hline
\end{tabular}


Table 3 Characteristics of sorbates

\begin{tabular}{lllccr}
\hline Sorbate & & $\begin{array}{l}\text { Evaporation enthalpy } \\
(\mathrm{kJ} / \mathrm{mol})\end{array}$ & $\begin{array}{l}\text { Saturation pressure } \\
(\mathrm{Pa})\end{array}$ & \multicolumn{2}{c}{$\begin{array}{l}\text { Molar volume } \\
\left(\mathrm{cm}^{3} / \mathrm{mol}\right)\end{array}$} \\
\hline Hexane & $\mathrm{C}_{6} \mathrm{H}_{14}$ & 28.85 & 20169 & 131.57 & \multicolumn{1}{c}{$\begin{array}{c}\text { Molar weight } \\
(\mathrm{g} / \mathrm{mol})\end{array}$} \\
Heptane & $\mathrm{C}_{7} \mathrm{H}_{16}$ & 25.79 & 6094 & 146.24 & 106.18 \\
Octane & $\mathrm{C}_{8} \mathrm{H}_{18}$ & 22.98 & 1866 & 162.39 & 114.23 \\
Benzene & $\mathrm{C}_{6} \mathrm{H}_{6}$ & 33.80 & 12657 & 89.4 & 78.11 \\
Methanol & $\mathrm{CH}_{3} \mathrm{OH}$ & 33.41 & 15807 & 40.5 & 18.02 \\
Water & $\mathrm{H}_{2} \mathrm{O}$ & 41.32 & 3168 & 20 & 32.04 \\
\hline
\end{tabular}

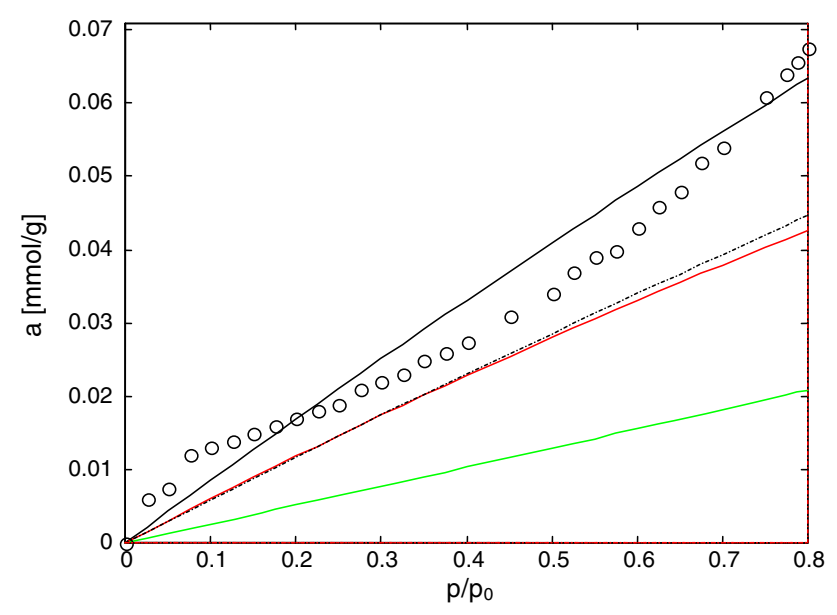

Fig. 1 Sorption isotherms of the W-35-hexane system viewed by subprocess. Key: circles experimental isotherm, lines, solid black total theoretical sorption solid red theoretical adsorption, solid green theoretical absorption, dotted black theoretical expansion (Color figure online)

shape state of the molecule. Molecules of such a shape could cover the submicropores and block it as a location for the next molecule.

\section{Results}

The results of the simulation experiment presented in Figs. 1, 2, 3, 4, 5, and 6 are exemplary. All theoretical isotherms are described in millimoles per gram of coal, the same units as the experimental ones.

Parameter $R$ (Fig. 2 and following even numbered Figs. up to Fig. 8) is calculated as a ratio of the pore radius to sorbate molecule radius. Molecule size is calculated using the state equation dedicated to this model (Milewska-Duda et al. 2000a). The whole sorption system is divided on an a priori basis into eleven subsystems with different dominant pore sizes. Subsystem $R=0$ depicts absorption and subsystem $R=1$ depicts pure adsorption. Intermediate subsystems are summarized in the expansion.

The system in Figs. 1 and 2 is nearly dual with a large amount of absorption and high expansion in the last

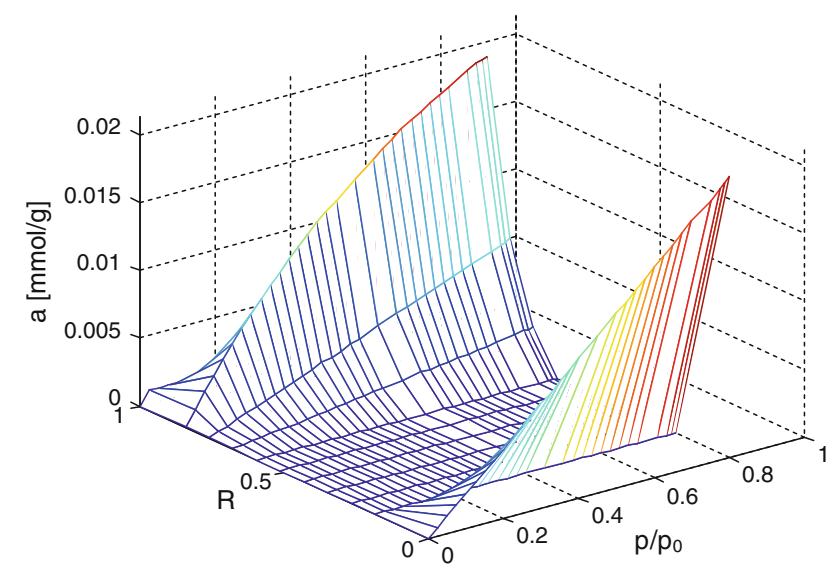

Fig. 2 Sorption isotherms of the W-35-hexane system versus submicropore size distribution. Axes: $R$ pore size distribution relative to molecule size, $p / p_{0}$ pressure relative to saturation pressure, $a$ sorption level (mmol/g)

expansion subsystem (near the adsorption one). Adsorption is weak in this sorption system. This situation could be the result of co-location of the chain molecule segments in the expansion and adsorption system (submicropores) with the number of contacts exceeding 6 , which according to the rules are assigned to the expansion. The surface imperfection found in the pore could cause the molecule to roll up. If this were to occur, the molecule would be allocated to the expansion, but really it would be part of the adsorption sub-system. It appears that molecules are deeply inserted into the submicropores, which results in high expansion.

The sorption system presented in Figs. 3 and 4 is similar to the previous one but the expansion system is not so expanded. Only one size of pores shows the expansion isotherm and again it is the one near the adsorption.

The character of the sorption system with octane (Figs. 5, 6) differs dramatically from the other ones presented. Adsorption is here the dominant subprocess. Such behavior supports the hypothesis of a plate-shape formulation, which is stronger with increasing length of chain. An alternative possibility is that molecules are partially located in submicropores and the remaining segments are 


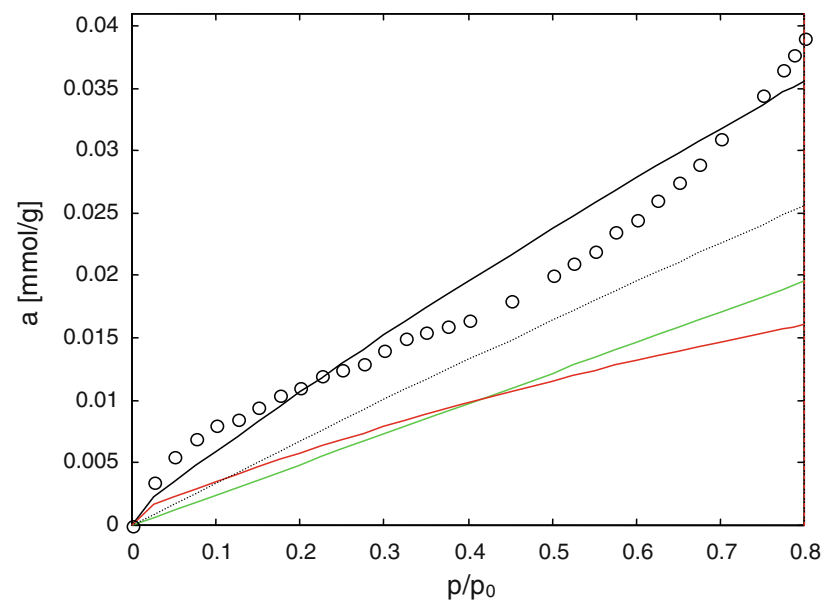

Fig. 3 Sorption isotherms of the W-35-heptane system viewed by subprocess. Key: circles experimental isotherm, lines, solid black total theoretical sorption, solid red theoretical adsorption, solid green theoretical absorption, dotted black theoretical expansion (Color figure online)

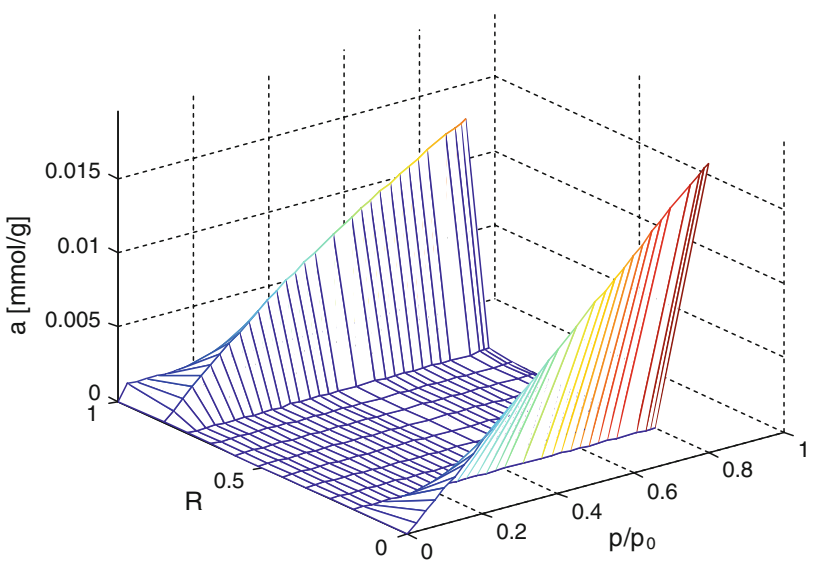

Fig. 4 Sorption isotherms of the W-35-heptane system versus submicropore size distribution. Axes: $R$ pore size distribution relative to molecule size, $p / p_{0}$ pressure relative to saturation pressure, $a$ sorption level $(\mathrm{mmol} / \mathrm{g})$

condensation centers for molecules from the next layers. But, it should be noted that the total sorption level decreases with increasing length of hydrocarbon chain. This is probably the result of blockage of the micropore outlet by the plate-shape of the hydrocarbon molecules due to its conformation on the surface.

The shape of the benzene sorption isotherm (Fig. 7) is similar to the shape of the hexane sorption isotherm. This suggests that the systems have similar states. It seems that aliphatic chains could form a plate-like shape to form the same figures as the crystallites of arenes in the surface of hard coal. Of course this only has an impact on part of the hexane molecules because the distribution of molecules in the submicropores has a different character for hexane and

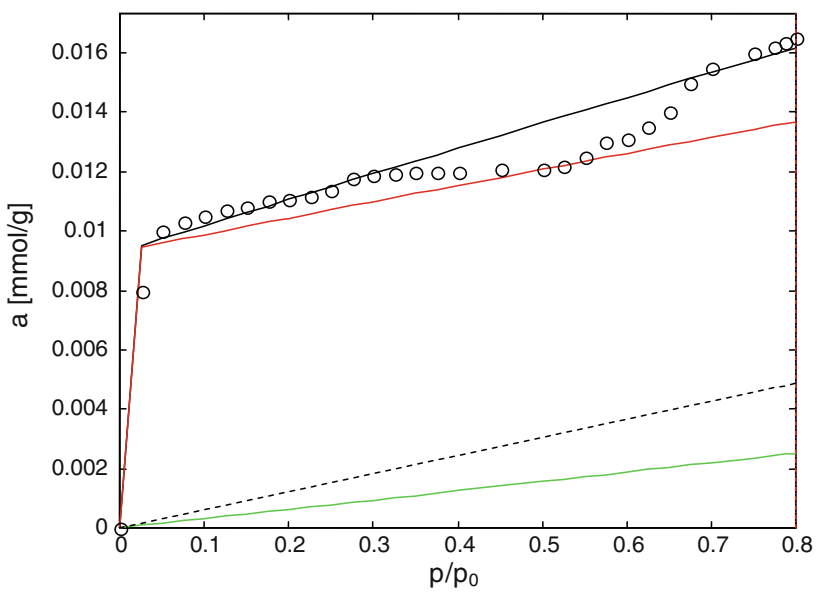

Fig. 5 Sorption isotherms of the W-35-octane system viewed by subprocess. Key: circles experimental isotherm, lines, solid black total theoretical sorption, solid red theoretical adsorption, solid green theoretical absorption, dotted black theoretical expansion (Color figure online)

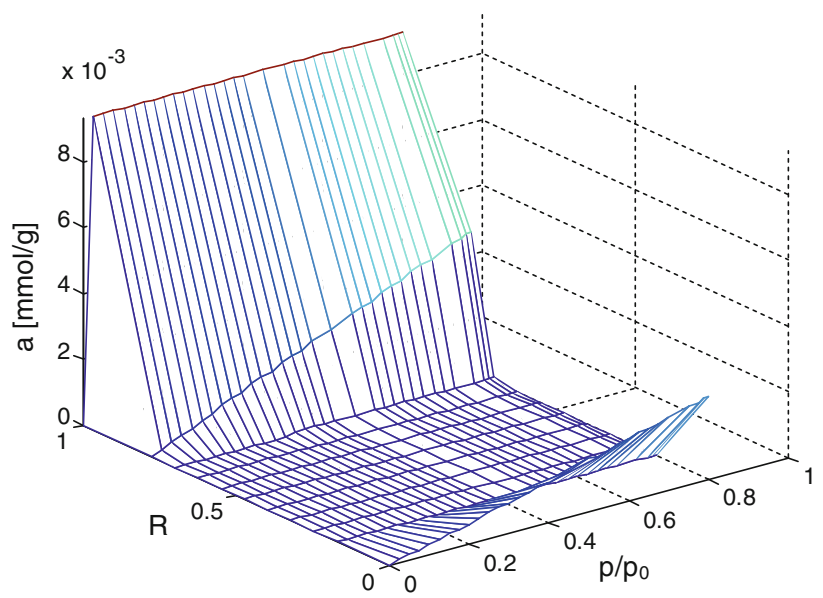

Fig. 6 Sorption isotherms of the W-35-octane system versus submicropore size distribution. Axes: $R$ pore size distribution relative to molecule size, $p / p_{0}$ pressure relative to saturation pressure, $a$ sorption level $(\mathrm{mmol} / \mathrm{g})$

for benzene (Fig. 8). However, the plate-like shape of the aliphatic molecules in the sorption system seems to be a good explanation for its low sorption capacity in comparison to benzene. This effect is stronger for longer chains (heptane and octane). Another reason for the higher benzene capacity is the interaction of $\pi$-electrons from arene crystallines and the benzene molecule in the sorption system, but the significance of this interaction should not be overestimated (Belov et al. 2009; Zyla et al. 1999).

More complicated interactions are observed on the isotherm chart for water (Fig. 9). This is caused by strong interaction between water molecules and the surface function groups and has the effect of strongly multilayer 


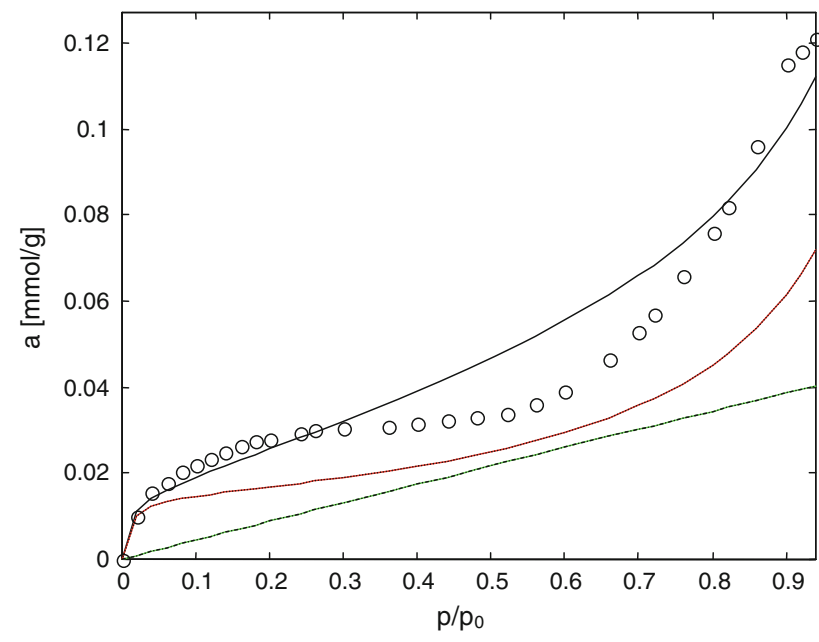

Fig. 7 Sorption isotherms of the W-35-benzene system viewed by subprocess. Key: circles experimental isotherm, lines, solid black total theoretical sorption, solid red theoretical adsorption, solid green theoretical absorption (here together with expansion (Color figure online)

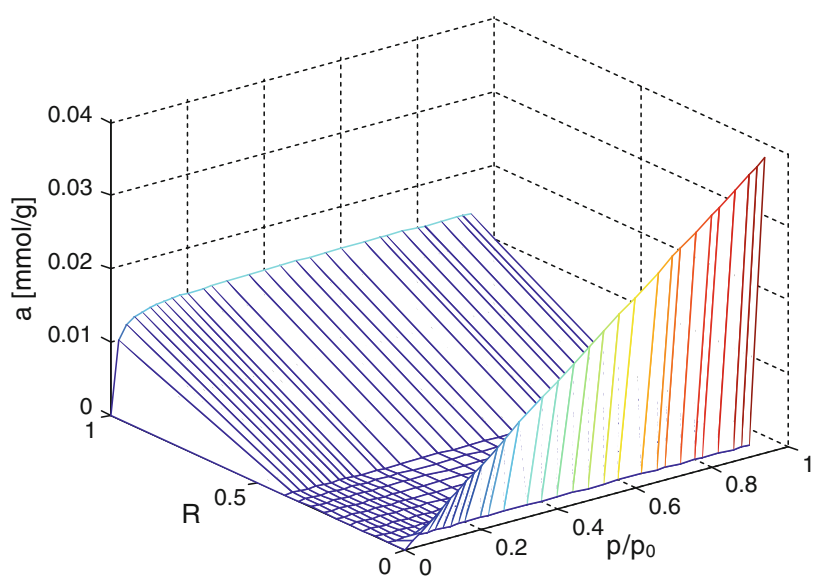

Fig. 8 Sorption isotherms of the W-35-benzene system versus submicropore size distribution. Axes: $R$ pore size distribution relative to molecule size, $p / p_{0}$ pressure relative to saturation pressure, $a$-sorption level $(\mathrm{mmol} / \mathrm{g})$

adsorption, but it is still possible to obtain monolayer capacity. What is interesting however is that the expansion in this sorption system is minimal. Water is a relatively good probe for indicating specific interactions and together with methanol gives reliable information on the structure of coal.

The methanol sorption isotherm chart (Fig. 10) shows the presence of a small quantity of molecules in the multilayer but adsorption is practically monolayer. Theoretical expansion appears at a higher level than water expansion. The rate of expansion to absorption for methanol is comparable to the rates for heptane and octane but hexane shows a greater difference in molecule location to the subsystems.

Figures 2, 4 and 6 show that no sorption system is really bimodal (namely adsorption + absorption) but expansion

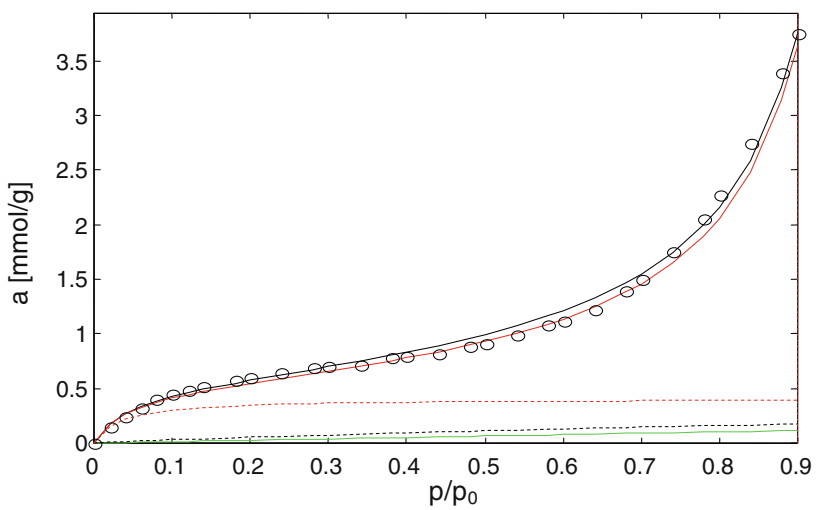

Fig. 9 Sorption isotherms of the W-35-water system viewed by subprocess. Key: circles experimental isotherm, lines, solid black total theoretical sorption, solid red theoretical monolayer adsorption, doted red theoretical multilayer adsorption, solid green theoretical absorption, doted black theoretical expansion (Color figure online)

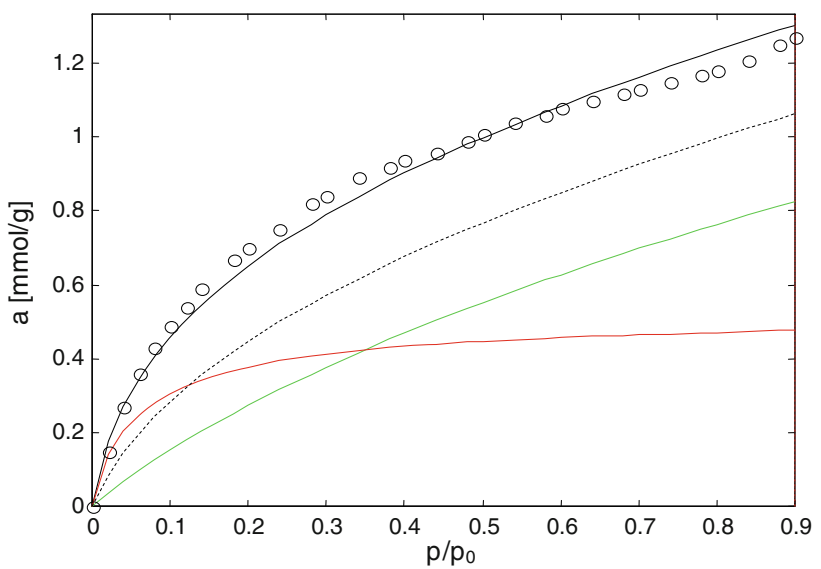

Fig. 10 Sorption isotherms of the W-35-methanol system by subprocess. Key: circles experimental isotherm, lines, solid black total theoretical sorption, solid red theoretical adsorption, solid green theoretical absorption, doted black theoretical expansion circles experimental isotherm, lines, solid black total theoretical sorption, solid red theoretical adsorption, solid green theoretical absorption, doted black theoretical expansion (Color figure online)

is in fact a major participant in the process. The benzene sorption system is the one and only bimodal system in the range of systems investigated. The same difficulty in fitting the experimental isotherms to the theoretical sorption isotherms arises as an effect of the complicated location of the molecule which results in the assignment of molecule segments to both the expansion and adsorption subprocesses.

Tables 4 and 5 give details of the characteristics of sorption systems. $\mathrm{V}_{\mathrm{h}}^{\mathrm{ad}}$ is volume of adsorbed hydrocarbon molecules, $\mathrm{V}_{\mathrm{h}}^{\mathrm{t}}$ is the total capacity of the sorption system. $\mathrm{Z}_{\mathrm{A}} / \mathrm{Z}_{\mathrm{B}}$ is the ratio of molecular contacts in the sorption 
Table 4 Volumes of adsorbed molecules $\left(\mathrm{V}_{\mathrm{h}}^{\text {ad }}\right)$ and sorption capacity $\left(\mathrm{V}_{\mathrm{h}}^{\mathrm{t}}\right)$

\begin{tabular}{llllllll}
\hline Sample & \multicolumn{2}{c}{$\mathrm{V}_{\mathrm{h}}^{\mathrm{ad}}\left(\mathrm{cm}^{3} / \mathrm{g}\right)$} & & & \multicolumn{2}{c}{$\mathrm{V}_{\mathrm{h}}^{\mathrm{t}}\left(\mathrm{cm}^{3} / \mathrm{g}\right)$} \\
\cline { 2 - 7 } & $\mathrm{C}_{6} \mathrm{H}_{14}$ & $\mathrm{C}_{7} \mathrm{H}_{16}$ & $\mathrm{C}_{8} \mathrm{H}_{18}$ & $\mathrm{C}_{6} \mathrm{H}_{6}$ & $\mathrm{H}_{2} \mathrm{O}$ & $\mathrm{CH}_{3} \mathrm{OH}$ & 0.039 \\
$\mathrm{~W}-31$ & 0.0006 & 0.0006 & 0.0001 & n.a. & 0.07 & 0.0282 \\
$\mathrm{~W}-33$ & 0.0005 & 0.0005 & 0.0005 & n.a. & 0.013 & 0.005 & 0.0734 \\
$\mathrm{~W}-35$ & 0 & 0.0001 & 0.0013 & 0.0066 & 0.007 & 0.001 & 0.0579 \\
\hline
\end{tabular}

Table 5 Coefficients describing the influence of shape on molecular contacts $\left(Z_{A} / Z_{B}\right)$

\begin{tabular}{|c|c|c|c|c|c|c|}
\hline \multirow[t]{2}{*}{ Sample } & \multicolumn{6}{|l|}{$\mathrm{Z}_{\mathrm{A}} / \mathrm{Z}_{\mathrm{B}}$} \\
\hline & $\mathrm{C}_{6} \mathrm{H}_{14}$ & $\mathrm{C}_{7} \mathrm{H}_{16}$ & $\mathrm{C}_{8} \mathrm{H}_{18}$ & $\mathrm{C}_{6} \mathrm{H}_{6}$ & $\mathrm{H}_{2} \mathrm{O} *$ & $\mathrm{CH}_{3} \mathrm{OH}$ \\
\hline $\mathrm{W}-31$ & $0.80 / 0.77$ & $0.88 / 0.53$ & $0.91 / 0.81$ & n.a. & $1.06 / 0.78$ & $0.83 / 0.75$ \\
\hline W-33 & $0.77 / 0.50$ & $0.60 / 0.65$ & $0.8 / 0.55$ & n.a. & $1.18 / 0.837$ & $0.949 / 0.73$ \\
\hline W-35 & $0.70 / 0.75$ & $0.73 / 0.52$ & $0.79 / 0.56$ & $0.85 / 0.83$ & $1.23 / 0.99$ & $0.91 / 0.91$ \\
\hline
\end{tabular}

* The value is given in the form $\mathrm{C}_{\mathrm{pA}} \times \mathrm{Z}_{\mathrm{A}} / \mathrm{Z}_{\mathrm{B}}$, where $\mathrm{C}_{\mathrm{pA}}$ is the coefficient describing the specific interactions of water and surface groups

system in small and larger micropores, respectively. The criterion for division is medium pore size understood as a maximum of capacity distribution.

The results of the computation permit us to state that chain molecules (e.g. hexane) adopt a plate-like or globular shape (Zyla et al. 1999; Jodlowski and Wójcik 2003). The volume of adsorbed molecules $\left(\mathrm{V}_{\mathrm{h}}^{\mathrm{ad}}\right)$ for each sorbate is significantly lower than accessible pore capacity $\left(\mathrm{V}_{\mathrm{h}}^{\mathrm{t}}\right)$, with the exception of the water sorbate, which is an effect of the specific interactions involved and multilayer adsorption. Such a phenomenon is caused by the blocking of pores by the plate-like shape of chain molecules adsorbed onto the surface. A significant change occurs with the adsorption of octane. The degree of surface use $\left(\mathrm{V}_{\mathrm{h}}^{\mathrm{ad}} / \mathrm{V}_{\mathrm{h}}^{\mathrm{t}}\right.$ ratio) as well as the adsorption to absorption ratio is greater for octane than for hexane and heptane. It seems that the greater opportunity for making a plate-like or globular shape in the longest chain molecule causes a better fit of the molecule to the pore structure. Simultaneously monolayer capacities calculated from hexane and cyclohexane are nearly the same which in connection with the fact that total adsorption capacity of hexane is ten times greater shows that the adsorption of hexane is evidently multilayer. Moreover the location of the hexane molecule on the surface has another effect: part of the molecule is inserted into the pore, part is on the external surface or is unabsorbed creating the adsorption centre for the next molecules.

\section{Conclusions}

The simplifying assumption on the negligible influence of a molecule's location order is not precise and should be reconsidered. Simple molecule sorbates (e.g. water or methanol) give very good estimates for theoretical isotherms and reliable parameters of coal structure and the state of the sorption system. Aliphatic-chain molecule sorbates gives a little bit less reliable estimates. Such items should not be used for the identification of coal structure together with the state of the sorption system. Nevertheless MSM is a useful tool for sorption process analysis in complex sorbents like hard coal. The model will let us derive absorption, adsorption and expansion subsystems from the sorption process with a detailed description of the porous system. Despite some inaccuracies in the information obtained, the hypothesis on the behavior of hard coal structure and molecules in the sorption system is worth making and checking. Comparative study of the sorption of different chain and ring molecules semi-simultaneously with water and methanol (not in mixture-separate isotherms are computed simultaneously with common coal structure parameters) provides the opportunity to obtain detailed information on the energetic and geometric properties of the sorption system, which could be the basis for the prediction of sorption and the technological properties of different systems with hard coal.

Acknowledgments This work has been carried out with the financial support of AGH-UST Statutory Research No. 11.11.210.213.

Open Access This article is distributed under the terms of the Creative Commons Attribution License which permits any use, distribution, and reproduction in any medium, provided the original author(s) and the source are credited.

\section{References}

Belov, N.A., Sheremet'eva, N.A., Yampolskii, YuP, Muzafarov, A.M.: Thermodynamics of the sorption of organic vapors in a 
carbosilane dendrimer and a hyperbranched polymer. Polym. Sci. Ser. A 51(5), 518-530 (2009)

Breus, I.P., Mishchenko, A.A., Potashev, K.A., Breus, V.A.: Description of organic compound vapor-phase sorption by geosorbents: adequacy of the isotherm approximation. Colloids Surf. A 276, 122-133 (2006)

Duda, J., Milewska-Duda, J.: A theoretical model for evaluation of configurational entropy of mixing with respect to shape and size of particles. J. Math. Chem. 17, 69 (1995)

Flory, J.P.: Principles of Polymer Chemistry. Cornell University Press, New York (1953)

Fugassi, P., Hudson, R., Ostapchenko, G.: The interaction of organic vapours with coal.1. The reversible sorption of methanol and pentane. Fuel 37(1), 25-28 (1958)

Jodłowski, G.S., Wójcik, M.: Sorption of organic sorbates on the hard coal in the light of multiple sorption model. Ann. Polym. Chem. Soc. 2, 1173-1176 (2003)

Lasoń, M., Żyła, M.: Aparatura do wyznaczania izoterm sorpcji i desorpcji par metodą mikrobiuretek cieczowych. Chem. Anal. (Warsaw) 8, 283 (1963). (in Polish)

Milewska-Duda, J., Duda, J.: Mathematical modeling of the sorption process in porous elastic materials. Langmuir 9, 3558-3566 (1993)
Milewska-Duda, J., Duda, J.T.: New BET-like models for heterogeneous adsorption in microporous adsorbents. Appl. Surf. Sci. 196, 115-125 (2002a)

Milewska-Duda, J., Duda, J.T.: A non-BET adsorption and its LgBET model. Colloids Surf. A 208, 71-81 (2002b)

Milewska-Duda, J., Duda, J., Jodłowski, G., Wójcik, M.: A new state equation for sorptives in near-critical and overcritical temperature regions. Langmuir 16, 6601-6612 (2000a)

Milewska-Duda, J., Duda, J.T., Jodłowski, G., Kwiatkowski, M.: A model for multilayer adsorption of small molecules in microporous materials. Langmuir 16, 7294-7303 (2000b)

Shi, X., Fu, H., Li, Y., Mao, J., Zheng, S., Zhu, Dongqiang: Impact of coal structural heterogeneity on the nonideal sorption of organic contaminants. Environ. Toxicol. Chem. 30(6), 1310-1319 (2011)

Shimizu, K., Takanohashi, T., Iino, M.: Sorption behaviors of various organic vapors to argonne premium coal samples. Energy Fuels 12(5), 891-896 (1998)

Żyła, M., Jodłowski, G.S., Wójcik, M.: Surface chemistry and porosity of hard coals in the light of sorption investigations. Fyzika. Chemie. Sbornik Prací Prirodovedecké Fakulty Ostravské Univerzity 7, 15-32 (1999) 